\title{
VISUAL METHODS IN EVENT STUDIES
}

\author{
TOMAS PERNECKY* AND TIJANA RAKIĆ† \\ *School of Hospitality and Tourism, Faculty of Culture and Society, Auckland University of Technology, \\ Auckland, New Zealand \\ †School of Sport and Service Management, University of Brighton, Eastbourne, UK
}

\begin{abstract}
Following the early articulation of event studies and the recent calls for philosophical and conceptual broadening of this emerging field, it is timely to engage with, and promote, a range of methodological approaches. Visual methods not only enable a richer and deeper understanding of events phenomena, the visuals collected or created as a part of a research project can facilitate the dissemination of findings to wider audiences. Whereas the overall aim of the special issue is to provide an overview of visual methods and inspire thinking in this area, this introductory article focuses mainly on wider conceptual and theoretical matters. It offers critical concepts and probing questions aimed at stimulating visual inquiry, along with a framework designed to capture the complexity and scope of visual inquiry in events.
\end{abstract}

\section{Key words: Critical event studies; Critical event visualities; Visual methods; Visual event studies}

\section{Introduction}

It is pertinent to begin by acknowledging that the study of events has made notable progress with regard to the number of academic publications and also in its theoretical scope. As a response to the rapidly growing events industry in need of managerial knowhow and professionalization, the field of event management has been a fertile ground for providing important insights, business acumen, and valuable research. In addition to the managerial focus on planned events, event studies (e.g., see Getz, 2012; Merkel, 2017; Pernecky, 2016a; Rojek, 2013; Spracklen \& Lamond, 2016) emerged to further investigate the social, cultural, political, and critical aspects of events, marking a clear distinction between the two fields. This demarcation is useful as both event management and event studies can further be enriched through the use of visual methods. The increased acceptance, recognition, and popularity of visual methodsobserved, for example, in the social sciences and humanities (e.g., Banks \& Zeitlyn, 2015; Hughes, 2012; Margolis \& Zunjarwad, 2017; Pink, 2012;

Address correspondence to Tomas Pernecky, Ph.D., School of Hospitality and Tourism, Faculty of Culture and Society, Auckland University of Technology, Private Bag 92006, Auckland 1142, New Zealand. Tel: +64 9-921-9999, ext. 6764; Fax: +64 9-921 9962; E-mail: tomas.pernecky@aut.ac.nz 
Rose, 2016) as well as in the sister field of tourism studies (e.g., see Rakić \& Chambers, 2012a)—means that researchers have access to additional tools.

By legitimizing the visual and the creative (see Mannay, 2015), event scholars and students are empowered to exercise more methodological freedom and gain a deeper understanding into what has been described as societal phenomena (Pernecky, 2014; Pernecky \& Moufakkir, 2014). Namely, visual methods do not only enable researchers to produce knowledge in innovative ways (Rakić \& Chambers, 2010), they can also be seen as a liberating and emancipatory force, whereby researchers, participants, and communities gain access to knowledge and expressions that might have not otherwise been accessible due to the inevitable strictures of traditional methods (see also discussions in Rakić \& Chambers, 2012a, 2012b). Accordingly, one of the aims of this article and the special issue at large is to establish visual methods as imperative in advancing future events research, and in cultivating epistemological and methodological diversity. Moreover, building on the momentum of visual methods in tourism scholarship (e.g., Feighey, 2003; Rakić, 2010; Rakić \& Chambers, 2009, 2010, 2012a; Scarles, 2009, 2010), the task before us is to provide an initial overview and inspire further engagement with methodological creativity within what we see as a collective attempt to "visualize" the future of event studies (see also Rakić \& Pernecky, this issue).

This article is organized into five thematic sections. Following from the introduction, the next part focuses on events as objects of visual analyses and notes the difference between the anecdotal use of images in academic writing and visual methods. Sections three and four concentrate on the philosophical, political, and theoretical deliberations, including what we have termed critical event visualities - described simply as the intersection of visual methods and critical approaches to the study of events. Also incorporated in section four is a visual aid, titled "The Visual Echoes of Events," demonstrating the scope and complexity of visual events research. Complemented with a selection of critical concepts and guiding questions, it sets the agenda for future visual inquiry into events. The final section outlines the contributions selected for this special issue.

\section{Events as Objects of Visual Analyses}

Events are similar to "places" in the context of tourism in that these are also "consumed" (Rakić \& Chambers, 2012c) through multisensory embodied experiences of being at an event and relying on all of our senses-visual, auditory, tactile, taste, and smell. Planned events in particular are often carefully orchestrated to leave a unique imprint on our senses, lending themselves to methodological creativity. In this regard, visual methods in the form of (audio)visual data created by either the researcher or research participants can facilitate a richer understanding of such experiences (Rakić \& Chambers, 2012b).

There are other ways in which the visual transpires in the event management industry. For example, risk managers use visual techniques to identify crowding issues; still and moving images are employed in promotional materials-conveying both the intangible event experience as well as the meanings attached to event brands; sales, sponsorship, and PR teams rely on visual displays to attract and promote sponsors and to communicate with target markets; production managers use visual aids for the design, mapping, and control of different aspects of events; and event designers are always on the lookout for new ways to enhance participant experiences. Whether it is LED video mapping for megaevents, stage design, or visual content (e.g., video, film, hologram, animation, and motion graphics), the visual is firmly embedded within planned events.

Yet there is an important distinction between events as multisensory, visual phenomena and visual methods. Whereas the first has to do with the fact that events are temporary multisensory entities, the latter concerns a specific strategy for studying an array of visual manifestations. In other words, the use of visual data to highlight an aspect of an event (e.g., an illustration in the findings section of an article or a thesis) does not amount to a visual method. A photograph taken at a festival may be helpful in describing a specific attribute of an event, but such use is only secondary and complementary. In contrast, visual research is a deliberate, systematic, and well-thought-through process implemented by the researcher(s) or their research participant(s) in the act of producing knowledge. It includes decisions about what kind of visual data ought to be collected and/or 
created, how it will be used and analyzed, by whom, and for what purpose. Importantly, careful thought has to be given to all of the processes: from data collection/data creation to subsequent analysis, interpretation, and incorporation in scholarly outputs.

Although the practical aspects of visual events research are detailed in the final article in this special issue, we will briefly turn our attention to clarifying some of the common misunderstandings. First, it is important to establish that visual methods and data, as noted by Pink (2013), are rarely purely visual. Visual data often contain text (e.g., posters) and, in this regard, both the image and the text need to be included in the analysis. Second, it is popular for visual methods to be implemented as part of qualitative approaches; however, that does not exclude them from quantitative research designs and projects underpinned by mixed methods. For instance, visual elements can be built into surveys and questionnaires. Third, visual methods can be combined with other methods in multimethod approaches, as highlighted in the work on multimodality by Jewitt (2009, see also van Leeuwen \& Jewitt, 2001). Jewitt (2009) describes multimodality as "approaches that understand communication and representation to be more than about language” (p. 14). Thus, images, gestures, speech, gaze, and the use of spaces in communication, interaction, and representation can all form the premise of multimodal analysis. In unison with most visual researchers, multimodality is especially important in those fields where speech and writing are no longer "adequate in understanding representation and communication" (Jewitt, 2009, p. 3). Arguably, event studies in general, and critical event studies in particular, require a variety of tools-including the visual- to facilitate understanding of the nonlinguistic aspects of events.

Despite the long history and use of visual methods in other disciplines, the multi-, inter-, and postdisciplinary fields of tourism, hospitality, and events have lagged behind these developments (see also Rakić \& Chambers, 2012a). It is worth noting that visual methods have been widely used in several different ways and extend to the following: (1) analyses of visuals such as still and moving images obtained from secondary sources; (2) creation of visuals such as photographs, videos, drawings, artwork, and mapping by researchers or their research participants for the purposes of a research project; and (3) reliance on visuals such as photographs, souvenirs, or videos in eliciting richer responses during interviews (Rakić \& Chambers, 2012b). In addition, uniquely to events, visual methods can also be used to produce a deliberate research setting (evental research) - a form of evental elicitation, detailed in the contribution by Lamond and Agar (this issue). We return to these themes in greater detail in the final contribution to this special issue (Rakić \& Pernecky, this issue).

\section{Philosophical and Political Deliberations}

As far as philosophical decisions and the research process in concerned, there are different strategies to using visual data. For instance, under the premise of realism, images serve as evidence or records of existing phenomena; for poststructuralists, whose ontological positions will vary on the continuum from critical/historic/value-laden realism to relativism, images have an important role in the construction of reality-operating as part of "a regime of truth"; and in semiotics, images can be the object of analysis within which wider cultural significance and ideological messages are uncovered (Knowles \& Sweetman, 2004). In this context, visuals can be seen as "representations of [a] reality as perceived and recorded by the person who created the image in a particular context of time and space” (Rakić, 2012, p. 23). Depending on one's philosophical orientation, a visual image can also be viewed as "evidence of reality 'captured' in an image which, used as scientific data, can in turn be used to create objective scientific knowledge" (Rakić, 2012, p. 23). Therefore, one has to consider the role of visual data in the overall research process and ensure alignment with the underlying philosophical assumptions.

A good start may be to ascertain whether visual methods are employed as a means or as an orientation (Pernecky, 2016d). When taken as a means, they serve a largely functional purpose-a means to an end. This way, they can be exercised in studying visual and symbolic elements in festival advertising, for example, as shown in work by Sel and Aktas (this issue). However, when researchers have deeper concerns that are intertwined with processes of acquiring knowledge and/or the implications for various stakeholders, visual methods become 
a (critical) orientation. In some circumstances, objects, experiences, and meanings may not be easily put into words, requiring other ways of facilitating understanding and transmitting knowledge. In this regard, valuable knowledge does not come only in numbers and a written form. Non-Western cultures have a rich history of storytelling, drawing, painting, singing, and performing-all of which can be studied and contextualized though visual methods. Indeed, one of the benefits of visual data, despite its inherent polysemic nature, is its capacity to communicate, relate, and convey information across languages and cultures. Hence, visual methods may be particularly important in the realms of indigenous scholarship and action research. They can be a vital aspect of the fight against epistemological and methodological purism grounded in Western thought, and be instrumental in overcoming "linguistic imperialism" (Mitchell, 1986) and the destabilization of cultural integrity. Furthermore, when combined with action research (e.g., Townsend, 2013) - particularly in the cases where such research results in both textual and visual research outputs - visual methods can facilitate a positive change and inspire communities into action. They, too, can become emancipatory by aiming "to liberate, enlighten or empower those people who are subjugated” (Alston \& Bowles, 2003, p. 14).

On the subject of visual emancipatory research, projects in this domain can concentrate on the vulnerable members of society impacted by events. Here, visual methods can be used to promote social justice, give participants a voice, and engage in a dialogue about a range of social problems (see e.g., Seedat, Suffla, \& Bawa, 2015). In practical terms, the method Photovoice (Wang \& Burris, 1997) can be employed at a local community level, and involve event participants, employees, and other stakeholders. It is worth emphasizing that visual methods can be instrumental in tackling a range of contemporary problems. For instance, given the rise in sexual abuse experienced at festivals and events (see Pernecky, Abdat, Brostroem, Mikaere, \& Paovale, 2019, in press), female participants can use it as a powerful tool to critically engage in a dialogue about this societal issue. In summary, visual methods combined with action, participatory, and emancipatory research can make a difference to vulnerable populations. These extend to people with disabilities, refugees and diasporic people, minority groups, and socioeconomically disadvantaged members of society.

\section{Conceptual and Theoretical Deliberations}

We have already established that events are inherently multisensory (and therefore also visual), and while acknowledging that they can be conceptualized as planned, unplanned, rhizomatic, creative outbursts, or novelty-bearing phenomena (for a summary of these definitions see Pernecky, 2016b), it is vital to note some of the developments in the field. In light of the emerging critical events scholarship (Lamond \& Platt, 2016; Merkel, 2017; Moufakkir \& Pernecky, 2014; Pernecky, 2016a; Pernecky \& Lück, 2013; Richards, de Brito, \& Wilks, 2013; Spracklen \& Lamond, 2016) and the recent outline of some of the theoretical approaches suitable for visual approaches to events (Zuev, 2016), there are now multiple ways in which events can be fathomed. The emerging theoretical and conceptual pluralism signals intellectual curiosity fueled by understanding events phenomena from a range of perspectives. By contemplating questions such as When is an event? (Pernecky, 2016c), researchers can go beyond the normative events grammar (mega-, major, minor, hallmark, sporting events) and claim new conceptual territories. On this front, there have been several recent contributions, such as the theoretical lenses of mobilities (Hannam, 2016) and worldmaking (Hollinshead \& Suleman, 2016; Pernecky, 2014) and the notion of eventification (Hauptfleish, 2016) and evental approaches to the study of events (Lamond \& Ager, this issue; MacKenzie \& Porter, 2016). Much of this work is a foray into what can be broadly termed as critical scholarship.

It is important to point out that critical inquiries into events are not new, although the recent coining of the term critical event studies (Spracklen \& Lamond, 2016) may suggest otherwise. One of the difficulties is that critical contributions have been made outside the field of event studies and are located in other disciplines and fields (e.g., see Mansfield, Caudwell, Wheaton, \& Watson, 2017; Rojek, 2013; Scraton \& Flintoff, 2002). Over a decade ago, the critical turn in tourism studies was described as "a quiet revolution," gathering 
researchers interested in the work on identity, the body, gender, and poststructural theories (Ateljevic, Morgan, \& Pritchard, 2007). Some of these thinkers now contribute to knowledge on events and have long belonged to this wave of critical scholarship. Others continue to be situated in leisure sciences, women's studies, cultural geography, art and design, and other fields. The central point is that just as critical tourism studies was an opportunity to challenge dominant epistemologies in tourism and understand it within social, cultural, political, and economic milieus, the field of event studies is now witnessing similar mobilization.

Consequently, events are seen as sociocultural/ political manifestations that occur on personal, local, national, and global levels, but also as a worldmaking force-speaking of how societies are made and remade. Events are no longer simply managerial entities - a point labored extensively elsewhere (Lamond \& Platt, 2016; Moufakkir \& Pernecky, 2014; Pernecky, 2016a; Spracklen \& Lamond, 2016) —but also displays of class, race, power, sexuality, ethnicity, inequality, oppression, and social injustice. Moreover, the way these issues are studied, and what is communicated and assimilated through events, is intertwined with numerous visual aspects and processes. Here, visual datawhether collected from secondary sources, created as part of a research project, or used for elicitation purposes (Rakić \& Chambers, 2012b)—become one of the core elements of the research process in facilitating critical inquiry.

\section{Critical Event Visualities}

When critical approaches to the study of events are combined with visual methods, we obtain what we have termed here critical event visualities. Included under this wide canopy are, for example, indigenous visualities (see Cummings, 2011), whereby individual and collective identities are constituted, represented, and mediated in visual forms. In the Foucauldian tradition, critical visual methodology tends to ask questions such as, "what is made visible through the signifying practices of art, what is made visible through or obscured in the exegesis or ekphrasis of an image, and how [do] specific visualities interrelate with specific signifying practices” (Linnell, 2010, p. 45).
Critical event visualities also speak to matters of representation, normalization, domination, and power. In this regard, in the process of dereifying images, one is tasked with analyzing the institutions (local, national, global) that play a part in inequality and injustice (Kurasawa, 2009). Following Bauman's (2000) notion of liquid modernity, Hollinshead, Kuon, and Alajmi (2014) have argued that events are a means for negotiation, communication, and play, and are thus important in helping us understand "the limits and the freedoms of who can do what to which and whom, and when, where and how, via the presentation of events and the performances of and about people, places, past and presents” (p. 13). Hollinshead et al. (2014) have produced a number of concepts devised specifically for events scholars; these can be fruitfully incorporated in critical event visualities and are noted in Table 1.

The critical vocabulary presented in Table 1 may be especially valuable for emerging scholars and students as visual material has to be made sense of, analyzed, theoretically "processed," and interpreted. Accordingly, the notions of evocation, effectivity, inscription, and subjugation can be of immense help when visual approaches to events are combined with examining the underlying ideological processes and mechanisms. Interrelated with this critico-theoretical analysis of visual materials are also matters of communication. The obvious questions that arise include: what is being communicated by whom, to whom, and for what purpose?

Hence, under the rubric of critical event visualities, we invite scholars and students to pay attention to the ways in which images and artefacts are turned into powerful tools of persuasion-capable of shaping public symbolic actions. Such concerns have been addressed as part of visual rhetoric. Olson, Finnegan, and Hope (2008) explained that "image makers use visualizations to record, document, investigate, instruct, report, thrill, excite, entertain, sell, and often to persuade" (p. 3). Furthermore, when combined with the practice and theory of rhetoric, visual rhetoric is concerned with naming "those symbolic actions enacted primarily through visual means, made meaningful through culturally derived ways of looking and seeing and endeavoring to influence diverse publics” (p. 3). The following thematic categories are adapted from 
Table 1

Concepts on Matters of Normalization and Naturalization

- coding machine: the function of an event to inscribe a people/place/past/present in terms of a particular (contested) worldview;

- effectivity: the degree to which an event moves the perception of others (or target interest groups) towards supporting a particular version of things, or otherwise take up an advocated identity or inheritances;

- emplotment: the telling of an event in terms of the interpretations used to narrate it, and the decorative exhilaration harnessed to make it captivating;

- evocation: the interpretive effort to dress up an event so that it speaks to the specific and important doxa (or cultural warrants/ held beliefs) of a particular homeland or target population;

- iconology: the political science study of how power is mobilised in the staging of a local/regional/national event vis-à-vis the operational deployment of resonant images, symbols and cultural significations it uses - i.e., perhaps of the iconography (or the iconology) of these images, symbols and cultural significances within a particular geographical, spatial, or temporal setting as obtained via ethnographic or representational mapping;

- inscription: the manner in which an event is textually (or discursively) explained/justified/narrated to suit a particular assumed normalised, or naturalised view of the world;

- invented culture: the process by and through which an event is used to help a population manufacture or remanufacture a presumed or claimed tradition for itself or to otherwise freshly/correctively help that population imagine/perform/develop 'new' yet supposedly bona fide cultural pursuits/traits/inheritances;

- material symbolism: the inherent power of signification that is embedded within the objects and the 'physical' icons used to project or propel an event, and the representational force of particular buildings or manufactured/produced/fabricated 'things' to speak to a given normalised worldview;

- performative activity: the selected mix of interactive pursuits and engaged activities which are selected for an event or which otherwise unfold at an event - which help (in an emergent sense) to freshly/correctively/creatively 'produce' in dynamic fashion new or revised forms of lived culture for or amongst that population;

- priviligentia: the 'ruling group' (or otherwise, the recipient group) which benefits economically/psychically/politically from the presentation of a particular event, the narratives of which are loaded consciously or unconsciously in terms of their interests or their cherished inheritances;

- sacralisation: the emic processes by and through which an event 'sacralises' an important idea or inheritance, whereby that belief/place/object or even that 'person' or 'being' is declared to be extremely rare/precious/sanctified by (or for) a specific people; and,

- subjugation: the manner in which a mainstream population or a hegemonic institution consciously or unconsciously uses its dominant resources or its communicative position at an event to suppress or silence the held truths, the believed rights, or the standing practices of a 'different', or 'rival', or an 'othered' community/group/organisation.

Note. From "Events in the Liquid Modern World: The Call for Fluid Acumen in the Presentation of Peoples, Places, Pasts and Presents” by K. Hollinshead, V. Kuon, and M. Alajmi, in O. Moufakkir and T. Pernecky (Eds.), Ideological, social and Cultural Aspects of Events pp. 19-20), 2014, Wallingford, UK: CAB International. Copyright 2014 by CAB International. Reproduced with permission of the Licensor through PLSclear.

Olson et al. (2008) and accompanied by questions adjusted for critical events research.

Performing and Seeing. Speaks to the symbolic actions that transpire through events, including the reproduction of racial classifications, stereotypes, economic class, and gender and sex roles. Probing questions in this category include:

- Who has the authority to perform the symbolic actions vis-à-vis events?

- Who is included and/or excluded, including by law or custom?

- Whose social standing is enhanced and/or undermined vis-à-vis events?

- How does the space or location change the conduct or performance?
- How are relationships of power reproduced visà-vis events?

- Who identifies/is empowered, who is offended/ alienated by the performance/event? (adapted from Olson et al., 2008, p. 15)

Remembering and Memorializing. Addresses the role of events in the practices, processes, and conversations about the past. Events have an active role in the acts of remembering, memorizing, signifying, and identity shaping. Probing questions in this category include:

- What is deemed worth of remembering or memorizing vis-à-vis events?

- What is ignored or deemed unworthy vis-à-vis events? 
- Which narratives get told vis-à-vis events?

- Whose voices are present and/or missing vis-àvis events?

- Who has the authority to make decisions about remembering and memorializing vis-à-vis events?

- To what extent do spectators participate in remembering and memorializing vis-à-vis events? (adapted from Olson et al., 2008, p. 99)

Confronting and Resisting. Concentrates on the capacity of events to disrupt and protest against the establishment. In this regard, Olson et al. (2008) noted that "visual performances of activism disrupt the presumption that citizens should always acquiesce to authoritative policies” (p. 199). Fueled by rhetoric of confrontation, resistance, and political activism, scholars may wish to ponder questions such as:

- How do visual actions exemplify resistance visà-vis events?

- How do actions of resistance incorporate visual rhetoric vis-à-vis events?

- How are power relations negotiated by marginalized groups vis-à-vis events?

- How are visualized forms of confrontation open to "reasonable" and "ethical" analysis as arguments vis-à-vis events? (adapted from Olson et al., 2008, p. 200)

Commodifying and Consuming. Tackles the issues of commodification and consumption in the context of events. Whereas commodification addresses how events are turned into "products," the latter examines how they are used or consumed. In this regard, commercial exchange is not isolated from the social, political, and cultural discourse (Olson et al., 2008), and for this reason, it is important to pay attention to the intersections between symbolic practices and commodities. This thematic category is increasingly relevant as we enter what Jensen (1999) foretold to be the "dream society," in which marketers have to commercialize emotions. Probing questions in this critical domain include:

- What visual strategies are used by event producers to achieve identification with visual commodities?
- What forms of visual persuasion are used by or at events?

- How are visual narratives structured to invite viewer participation in consumption practices vis-à-vis events?

- What audiences are "produced" through events by visual rhetoric devoted to consumption?

- What ethical issues arise in visual portrayals of consumption as identity vis-à-vis events? (adapted from Olson et al., 2008, p. 275)

Governing and Authorizing. Address the ways in which events are employed to exercise power and privilege, speaking to the "communicative practices of the politically powerful, economically resourceful, and socially privileged" (Olson et al., 2008, p. 327). With regard to the field of event studies, research in this area includes political campaigns and rallies, public events, and also other functions and forums. Probing questions in this category include:

- How do leaders and those in power use events to shape attitudes and beliefs?

- How are events used to mystify or clarify positions on substantive issues?

- How are events (mis)used for visual opportunities (e.g., careful image use, manipulation, and repetition)?

- In what ways do events authorize and consecrate political, legal, religious, education, and civic leaders to exercise leadership in their communities? (adapted from Olson et al., 2008, pp. 328-330)

\section{The Visual Echoes of Events}

In addition to fostering critical shrewdness, the final aid offered in this article is the concept of the visual echoes of events. Figure 1 highlights the numerous aspects of events that either lend themselves to the incorporation of visual material alongside traditional research methods to access knowledge that might have not been otherwise accessible or demand an exclusive reliance on one or more visual method(s). Designed primarily as a methodological tool for event scholars and students, it is also useful for capturing the complexity and 


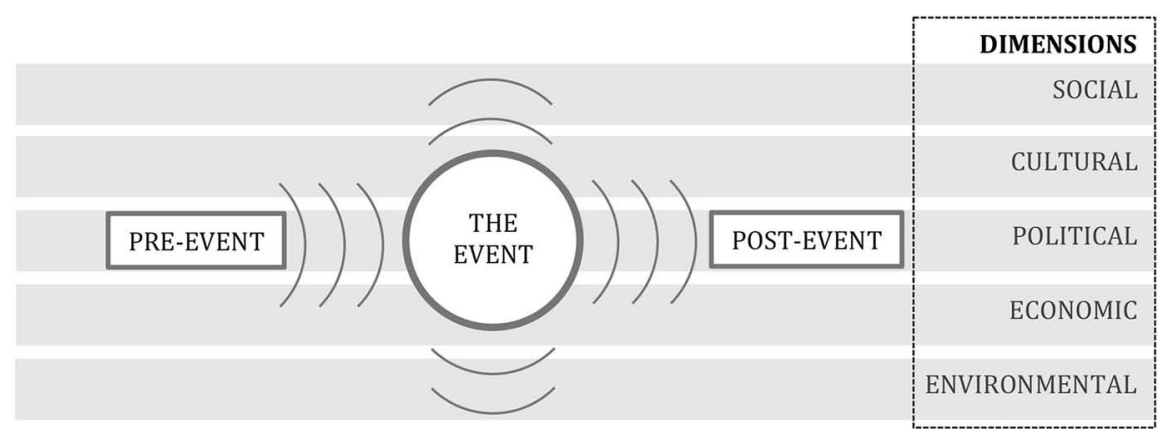

\begin{tabular}{|c|c|c|}
\hline $\begin{array}{l}\text { PRE-EVENT VISUALITIES } \\
\text { - } \quad \text { publicity and } \\
\text { marketing visuals } \\
\text { - } \text { posters } \\
\text { - planning documents } \\
\text { (maps, drawings, } \\
\text { diagrams) } \\
\text { - } \text { website content } \\
\text { - } \text { social media posts } \\
\text { and blogs } \\
\text { - media coverage } \\
\text { - wider social problems } \\
\text { and societal issues } \\
\text { related to the event } \\
\text { - pre-event primary } \\
\text { (visual) data } \\
\text { - etc. } \\
\text { visuals collected from secondary } \\
\text { sources for analysis / 'evental' } \\
\text { research, or used for elicitation }\end{array}$ & $\begin{array}{l}\text { ACTUAL EVENT VISUALITIES } \\
\text { - } \quad \text { visual aspects of the } \\
\text { actual event such as } \\
\text { drawings, artwork, } \\
\text { signage, stage and event } \\
\text { space set-up, lighting } \\
\text { - social media posts and } \\
\text { blogs } \\
\text { - } \quad \text { media coverage } \\
\text { - } \text { wider social problems } \\
\text { and societal issues } \\
\text { during the event } \\
\text { picturing practices, } \\
\text { performative aspects of } \\
\text { event attendance } \\
\text { at-event primary } \\
\text { (visual) data } \\
\text { etc. } \\
\text { visuals created by researcher(s) / } \\
\text { research participant(s)/ } \\
\text { screened/exhibited for purpose(s) } \\
\text { of 'evental' research, or collected } \\
\text { from secondary sources }\end{array}$ & $\begin{array}{l}\text { POST-EVENT VISUALITIES } \\
\text { - } \quad \text { post-event publicity } \\
\text { and media coverage } \\
\text { - } \quad \text { post-event social } \\
\text { media posts and blog } \\
\text { narratives } \\
\text { - } \text { memorabilia } \\
\text { reactions from } \\
\text { stakeholders } \\
\text { relationship between } \\
\text { the event and wider } \\
\text { social problems and } \\
\text { societal issues (e.g., } \\
\text { drugs, sexual abuse, } \\
\text { nationalism) } \\
\text { post-event primary } \\
\text { (visual) data } \\
\text { etc. } \\
\text { visuals collected from secondary } \\
\text { sources, or used for purpose(s) } \\
\text { of elicitation }\end{array}$ \\
\hline
\end{tabular}

Figure 1. The visual echoes of events.

scope of visual inquiry in events. It alerts researchers to the kinds of visualities that precede, take place during, and follow after the event. Depending on the typology and conceptual treatment employed, each event makes a unique visual footprint. Hence, local community events are different to hallmark events, which are different to protests and rhizomatic events, which, again, are different to, say, evental research (see Lamond \& Ager, this issue). Moreover, in conjunction with the aforementioned theoretical concerns, these visual echoes may reverberate across social, cultural, political, economic, and environmental dimensions-providing additional lenses through which events phenomena can be investigated.
The visual echoes of events are determined by the nature, size, and specific characteristics of the event itself. Figure 1 shows that, in addition to the value of visual methods in accessing deeper and richer understandings (e.g., the performative aspects of event attendance through a visual ethnographic approach, etc.), there may also be particular eventrelated visualities examined prior to, throughout, and after the event. With regard to the preevent visualities noted in Figure 1, suitable research material in this category includes visuals produced by event organizers, such as posters, diagrams, videos and promotional material, and visual commentaries and media coverage by external stakeholders. Included here are also concerns raised by different 
groups prior to the event-be they local community members, activists, or lobby groups. Promotional material and posters can be particularly valuable in studying the construction of identities (national, regional, cosmopolitan, or local), and scrutinized by means of discourse or semiotic analyses.

As events unfold, there are numerous opportunities to gather either primary or secondary visual data. The actual event visualities connote mainly, but not solely, the kind of data that can be created either by the researcher, the research participants, or both, at the event. Hence, festival attendees can document their experience while immersed in the event, researchers can gather visual material in the field, and they can also study posts to social media and live streaming throughout the event. Social media monitoring and media coverage during the event can be examined in depth and compared with pre and postevent visualities. Another possibility is to produce evental research (see Lamond \& Agar, this issue), whereby carefully orchestrated visualities may be deployed to create a liminoid environment as a way of exploring activism and provoking reactions from audiences. Other visual foci include artwork, signage, drawings, lighting, and spatial design, to name a few.

The third segment of postevent visualities gives examples of visual material typically collected from secondary sources, such as postevent publicity, media coverage, blogs, posts, commentaries, and reactions from stakeholders (e.g., local communities). Memorabilia and objects of remembrance also fall in this category and can be used in elicitation processes. In all stages - preevent, the event itself, postevent-researchers may examine wider societal problems and societal issues that manifest through/have contributed to/are inscribed into the event. In this regard, visual imagery is often used deliberately to position the event and to appeal to audiences-i.e., through storytelling, invoking memories, and making links to historical, social, and political occurrences. In addition, acts of violence, accidents, and safety issues can be studied by employing visual methods techniques.

It is indeed possible to collect primary visual data not only during the actual event, but also prior to and after the event. For instance, participants and stakeholders may be asked to produce drawings, create mind maps, and engage in photographic memoirs. This is noted within the model in Figure 1 as preevent primary (visual) data, at-event primary (visual) data, and postevent primary (visual) data. Hermeneutically inclined studies can further concentrate on examining events holistically and methodically, by scrutinizing in greater detail the elements presented in Figure 1. In this regard, it is important for researchers to bear in mind the project aim(s) and clearly articulate its scope, along with the theoretical and philosophical underpinnings. At this intersection, it ought to be reiterated that the purpose of the model is to bring to the fore the range and complexity of visual research; it is not an all-encompassing tool and will pose some limitations amid increasing theoretical and conceptual pluralism.

Lastly, in the context of critical event visualities, it is important to remember that events tell a (visual) story about hegemonic cultures and forms of power (e.g., hard power, soft power, revolutionary power, cultural hegemony, etc.; see Pernecky, 2014). Closed hegemonic cultures typically have low levels of organization and are linked to systematic oppression and injustice, whereas open hegemonic cultures have higher levels of organization displayed through protests, riots, and a richer tapestry of events. Importantly, one can examine the excluded, forgotten, segregated, and oppressed peoplesrendered invisible in the visual landscape. Whether such acts are deliberate, authorized, or unconscious, these form a significant aspect of critical event visualities, particularly when combined with the theoretical tools outlined earlier (see Hollinshead et al., 2014; Olson et al., 2008). What visual methods in this context can offer, in addition to hidden and multilayered understandings, is also the possibility for research projects to become both textual and visual outputs (such as documentaries) and reach audiences beyond academia (Rakić \& Chambers, 2010).

\section{Outline of Contributions to This Special Issue}

The articles chosen for this special issue showcase a wide variety of approaches to incorporating visual methods in events research. They are organized according to increasing levels of conceptual and theoretical complexity, which is not to imply that some contributions are less worthy; on the contrary, each makes a valuable addition. 
The difference lies in the application of visual methods, and the ways in which events are framed conceptually. There is a gradual shift from the implicit notion of "planned events"-notable in the first three articles (i.e., Walters; Sel \& Aktas; Goh, Smith, \& Yeoman) - to the concept of "eventification" (Porter) and the study of the "evental" (Rothmüller; Lamond \& Agar).

The first article, by Trudie Walters, investigates the relationship between fashion events and destination branding, showing that not only do events shape destinations - as articulated previously, for example, under the theoretical frameworks of worldmaking and placemaking (see Hollinshead \& Suleman, 2016; Pernecky, 2014; Richards, 2017) — destinations are also instrumental in influencing fashion. This is brought to our attention in a discussion of the "distinctive Dunedin look" and through careful sorting and coding of 1,000 pages of eventsrelated visual material and text. Walters' research highlights the entangled associations between fashion and place in the context of events.

The following article by Zehra Gokce Sel and Gurhan Aktas looks at printed advertising by studying 69 posters for the Cannes Film Festival between the years 1946 and 2016. By applying semiotic and content analyses, the authors reveal the evolving marketing strategies and dominant use of visual elements employed by the festival organizers. This is a good example of evaluating promotional visual material over a long period of time, including the signifier/signified elements and connotative/denotative meanings in communication with target audiences.

Sandra Goh, Karen Smith, and Ian Yeoman draw on an arts-informed life history approach to examine event travel trajectories of Singaporean artists and performers. Here, visual methods are employed as a reflexive tool, allowing the participants to visualize, plot, and produce memory maps. These are then integrated to generate more nuanced levels of understanding, as shown by the authors in their application of the Zoom Model.

Brooke Porter's work is headlined in terms of eventification (see Hauptfleish, 2016) and bridges ocean activism with events by focusing on the phenomenon of mermaiding and merfolk events. Termed as "enchanting events," Porter argues that these are important in spreading ocean awareness and conservation messages. In her view, enchanting events also have the potential to overcome the shortcomings of other conservation strategies and barriers to environmental action. As part of a multimethod approach, Porter combines visual data with nonvisual material, including the use of screenshots, podcasts, photographs, blog excerpts, videos, and social media. The findings culminate in a model that illustrates the process of "fantastic" learning through knowledge sharing platforms at enchanted events-making a contribution to both visual and critical event studies.

Ninette Rothmüller represents one of the contributors who, in light of the aforementioned distinction between event management and event studies, shows how visual methods can facilitate and advance novel conceptualizations. We are introduced to new vocabulary, such as the notions of "desire paths" and "turfing," whereby we are challenged to think of events in terms of the latter: "turfing.” In the words of Rothmüller:

\footnotetext{
The translation of the everyday situation into movement, into turfing, supports the notion of turfing as event, in the sense that it not only invites newness to the world but moreover supports an agency-based mode of survival and thus makes a crucial difference in performers' lives.
}

Underpinned by the work of Hannah Arendt, this contribution injects needed philosophical and theoretical richness into the field by visually examining the intersection between action, freedom, and politics.

The article by Ian Lamond and Laura Agar concentrates on augmented film screenings and nonfilm elements and examines the extent to which events of dissent act as disruptive raptures. Framed within the rhetoric of evental research, the authors argue that traditional social scientific research methods are insufficient in grasping and understanding the "evental." Hence, visual methods emerge as an important, if not necessary, tool in critical event studies research. It is worth noting that, in contrast to the other contributions, Lamond and Agar display how visual methods can be used in the conceptual stage to produce responses from participants and to instigate the evental. In this case, visual methods can be seen as a form of "evental elicitation" and be combined with other methods as part of the research project. 
Finally, the closing article (Rakić \& Pernecky) accentuates the importance of visual methods in the study of events phenomena, and addresses the conundrums, issues, and challenges often faced by researchers. Taken as a whole, this special issue has been carefully arranged to first situate visual methods theoretically and conceptually, followed by examples of current visual research, and concluding with practical suggestions. It should be useful for students and researchers interested in visual methods and in courses on methods.

\section{References}

Alston, M., \& Bowles, W. (2003). Research for social workers: An introduction to methods (2nd ed.). London, UK: Routledge.

Ateljevic, I., Morgan, N., \& Pritchard, A. (2007). Editors' introduction: Promoting an academy of hope in tourism enquiry. In I. Ateljevic, A. Pritchard, \& N. Morgan (Eds.), The critical turn in tourism studies: Innovative research methodologies (pp. 1-8). Amsterdam, The Netherlands: Elsevier.

Banks, M., \& Zeitlyn, D. (2015). Visual methods in social research. London, UK: Sage.

Bauman, Z. (2000). Liquid modernity. Cambridge, UK: Polity Press.

Cummings, D. K. (2011). Visualities: Perspectives on contemporary American Indian film and art. East Lansing, MI: Michigan State University Press.

Feighey, W. (2003). Negative image? Developing the visual in tourism research. Current Issues in Tourism, 6(1), 76-85.

Getz, D. (2012). Event studies: Theory, research and policy for planned events (2nd ed.). Abingdon, UK: Routledge.

Hannam, K. (2016). A mobilities approach to events. In T. Pernecky (Ed.), Approaches and methods in event studies (pp. 67-78). London, UK: Routledge.

Hauptfleish, T. (2016). Eventification: Framing the ordinary as extraordinary. In T. Pernecky (Ed.), Approaches and methods in event studies (pp. 36-52). London, UK: Routledge.

Hollinshead, K., Kuon, V., \& Alajmi, M. (2014). Events in the liquid modern world: The call for fluid acumen in the presentation of peoples, places, pasts and presents. In O. Moufakkir \& T. Pernecky (Eds.), Ideological, social and cultural aspects of events (pp. 12-27). Wallingford, UK: CABI.

Hollinshead, K., \& Suleman, R. (2016). Tourism and new collective effervescence: The encoding of "Aboriginality”a worldmaking critique of special events and special places. In T. Pernecky (Ed.), Approaches and methods in event studies (pp. 120-146). London, UK: Routledge.

Hughes, J. (2012). SAGE visual methods. London, UK: Sage.
Jensen, R. (1999). The dream society: How the coming shift from information to imagination will transform your business. New York, NY: McGraw-Hill Education.

Jewitt, C. (Ed.). (2009). The Routledge handbook of multimodal analysis. Abingdon, UK: Routledge.

Knowles, C., \& Sweetman, P. (Eds.). (2004). Picturing the social landscape: Visual methods and the sociological imagination. London, UK: Routledge.

Kurasawa, F. (2009). Humanitarianism and the representation of alterity: The aporias and prospects of cosmopolitan visuality. In S. Gaon (Ed.), Democracy in crisis: Violence, alterity, community (pp. 133-154). Manchester, UK: Manchester University Press.

Lamond, I. R., \& Platt, L. (Eds.). (2016). Critical event studies: Approaches to research. London, UK: Palgrave Macmillan.

Linnell, S. (2010). Art psychotherapy and narrative therapy: An account of practitioner research. Dubai, United Arab Emirates: Bentham Science Publishers.

MacKenzie, I., \& Porter, R. (2016). Evental approaches to the study of events. In T. Pernecky (Ed.), Approaches and methods in event studies (pp. 25-35). London, UK: Routledge.

Mannay, D. (2015). Visual, narrative and creative research methods: Application, reflection and ethics. London, UK: Routledge.

Mansfield, L., Caudwell, J., Wheaton, B., \& Watson, B. (2017). The Palgrave handbook of feminism and sport, leisure and physical education. London, UK: Palgrave Macmillan UK.

Margolis, E., \& Zunjarwad, R. (2017). Visual research. In N. K. Denzin \& Y. S. Lincoln (Eds.), The SAGE handbook of qualitative research (5th ed., pp. 600-626). London, UK: Sage.

Merkel, U. (Ed.). (2017). Power, politics and international events: Socio-cultural analyses of festivals and spectacles. London, UK: Routledge.

Mitchell, W. J. T. (1986). Iconology: Image, text, ideology. Chicago, IL: University of Chicago Press.

Moufakkir, O., \& Pernecky, T. (Eds.). (2014). Ideological, social and cultural aspects of events. Wallingford, UK: CABI.

Olson, L. C., Finnegan, C. A., \& Hope, D. S. (Eds.). (2008). Visual rhetoric: A reader in communication and American culture. London, UK: Sage.

Pernecky, T. (2014). The making of societies through events: On ideology, power and consent. In O. Moufakkir \& T. Pernecky (Eds.), Ideological, social and cultural aspects of events (pp. 28-46). Wallingford, UK: CABI.

Pernecky, T. (Ed.) (2016a). Approaches and methods in event studies. London, UK: Routledge.

Pernecky, T. (2016b). Epistemic foundations of event studies. In T. Pernecky (Ed.), Approaches and methods in event studies (pp. 3-21). London, UK: Routledge.

Pernecky, T. (2016c). What and when is an "event": A short prelude to event studies. In T. Pernecky (Ed.), Approaches and methods in event studies (pp. $\mathrm{xv}-\mathrm{Xvi}$ ). London, UK: Routledge. 
Pernecky, T. (2016d). Epistemology and metaphysics for qualitative research. London, UK: SAGE.

Pernecky, T., Abdat, S., Brostroem, B., Mikaere, D., \& Paovale, H. (2019, in press). Sexual harrassment at festivals and events: A student perspective. Event Management.

Pernecky, T., \& Lück, M. (Eds.). (2013). Events, society and sustainability: Critical and contemporary approaches. London, UK: Routledge.

Pernecky, T., \& Moufakkir, O. (2014). Events as societal phenomena. In O. Moufakkir \& T. Pernecky (Eds.), Ideological, social and cultural aspects of events (pp. 1-11). Wallingford, UK: CABI.

Pink, S. (2013). Doing visual ethnography (3rd ed.). London, UK: Sage.

Rakić, T. (2010). Tales from the field: Video and its potential for creating cultural tourism knowledge. In G. Richards \& W. Munsters (Eds.), New perspectives on cultural tourism research (pp. 129-140). Wallingford, UK: CABI.

Rakić, T. (2012). Philosophies of the visual (method) in tourism research. In T. Rakić \& D. Chambers (Eds.), An introduction to visual research methods in tourism (pp. 17-32). London, UK: Routledge.

Rakić, T., \& Chambers, D. (2009). Researcher with a movie camera: Visual ethnography in the field. Current Issues in Tourism, 12(3), 255-270.

Rakić, T., \& Chambers, D. (2010). Innovative techniques in tourism research: An exploration of visual methods and academic filmmaking. International Journal of Tourism Research, 12(4), 379-389.

Rakić, T., \& Chambers, D. (Eds.). (2012a). An introduction to visual research methods in tourism. London, UK: Routledge.

Rakić, T., \& Chambers, D. (2012b). Introducing visual methods to tourism studies. In T. Rakić \& D. Chambers (Eds.), An introduction to visual research methods in tourism (pp. 3-14). London, UK: Routledge.

Rakić, T., \& Chambers, D. (2012c). Rethinking the consumption of places. Annals of Tourism Research, 39(3), 1612-1633.
Richards, G. (2017). From place branding to placemaking: The role of events. International Journal of Event and Festival Management, 8(1), 8-23.

Richards, G., de Brito, M., \& Wilks, L. (Eds.). (2013). Exploring the social impacts of events. Abingdon, UK: Routledge.

Rojek, C. (2013). Event power: How global events manage and manipulate. London, UK: Sage.

Rose, G. (2016). Visual methodologies: An introduction to researching with visual materials (4th ed.). London, UK: Sage.

Scarles, C. (2009). Becoming tourist: Renegotiating the visual in the tourist experience. Environment and Planning D: Society and Space, 27, 465-488.

Scarles, C. (2010). Where words fail, visuals ignite: Opportunities for visual autoethnography in tourism research. Annals of Tourism Research, 37(4), 905-926.

Scraton, S., \& Flintoff, A. (2002). Gender and sport: A reader. London, UK: Routledge.

Seedat, M., Suffla, S., \& Bawa, U. (2015). Photovoice as emancipatory praxis: A visual methodology toward critical consciousness and social action. In D. Bretherton \& S. F. Law (Eds.), Methodologies in peace psychology: Peace research by peaceful means (pp. 309-324). London, UK: Springer.

Spracklen, K., \& Lamond, I. R. (2016). Critical event studies. London, UK: Routledge.

Townsend, A. (2013). Action research: The challenges of changing and researching practice. Maidenhead, UK: Open University Press.

van Leeuwen, T., \& Jewitt, C. (Eds.). (2001). Handbook of visual analysis. London, UK: Sage.

Wang, C., \& Burris, M. A. (1997). Photovoice: Concept, methodology, and use for participatory needs assessment. Health Education \& Behavior, 24(3), 369-387.

Zuev, D. (2016). Visual methods in event studies. In T. Pernecky (Ed.), Approaches and methods in event studies (pp. 96-119). London, UK: Routledge. 